\title{
Genetic Algorithms-Based Optimization of Cable Stayed Bridges
}

\author{
Venkat Lute $^{1}$, Akhil Upadhyay ${ }^{2}$, Krishna Kumar Singh ${ }^{3}$ \\ ${ }^{1}$ Civil Engineering Department, Gayatri Vidhya Parishad College of Engineering, Visakhapatnam, India; ${ }^{2}$ Civil Engineering Depart- \\ ment, Indian Institute of Technology Roorkee, Roorkee, India; ${ }^{3}$ Civil Engineering Department, Indian Institute of Technology Roor- \\ kee, Roorkee, India. \\ Email: lutevenkat@gmail.com, \{akhilfce, kks45fce\}@iitr.ernet.in
}

Received July 20 ${ }^{\text {th }}$, 2011; revised August $18^{\text {th }}$, 2011; accepted September $15^{\text {th }}, 2011$.

\begin{abstract}
Optimum design of cable stayed bridges depends on number of parameters. Design of Cable stayed bridge satisfying all practical constraints is challenging to the designers. Considering the huge number of design variables and practical constraints, Genetic Algorithms (GA) is most suitable for optimizing the cable stayed bridge. In the present work the optimum design is carried out by taking total material cost of bridge as objective function. During problem formulation most of the practical design variables and constraints are considered. Using genetic algorithms some parametric studies such as effect of geometric nonlinearity, effect of grouping of cables, effect of practical site constraints on tower height and side span, effect of bridge material, effect of cable layout, effect of extra-dosed bridges on optimum relative cost have been presented. Data base is prepared for new designers to estimate the relative cost of bridge.
\end{abstract}

Keywords: Cable Stayed Bridge, Genetic Algorithms, Stiffness Analysis

\section{Introduction}

The modern cable-stayed bridge consists of a superstructure of steel or reinforced concrete members supported at one or more points by cables, extending from one or more towers. The renewal of the cable-stayed system in modern bridge engineering was due to the tendency of bridge engineers to obtain optimum structural performance from material which was in short supply during the post-war years [1]. Due to their aesthetic appearance, efficient utilization of structural materials and other notable advantages, cable-stayed bridges have gained popularity in recent decades. This fact is due to the relatively small size of the substructures required and due to the advent of efficient construction techniques apart from the rapid progress in the analysis and design of this type of bridge. Dimensioning of particular bridge from economic consideration, meeting the safety and serviceability requirements is complicated due to wide possible range.

Cable stayed bridges are statically indeterminate structures and their structural behavior is largely affected by the cable arrangement, and stiffness distribution in the cable, deck, and pylons. The analysis of cable stayed bridges is discussed by [2,3], but the analysis is limited to a fixed geometry because it is based on impirical formulae.
References [4,5] have carried out parametric studies regarding the effect of cable, girder, and pylon stiffness on bridge behavior considering only linear analysis. Thus, in the present work rational approach for the analysis, including nonlinearities of cable stayed bridge is considered. Since GA requires very efficient and reasonable accurate analysis, the present stiffness based approach is most suitable for GA optimization. References [6,7] have investigated the cable anchorage position in girder, side-to-main span ratio and number of cables individually. However, the studies of effect of individual parameter on relative optimum cost of bridge do not carry much significance. Thus in the present work the optimization is carried out by considering more design parameters as design variables simultaneously. Reference [8] used GA for space truss optimization and [9] used the GA for the optimum design of fiber composite stiffened panels to study the robustness of GA in handling mixed types of variables. Reference [10] studied the application of genetic algorithms on optimum design of bridge decks. In optimizing cable stayed bridges, the cross sectional area of stiffening girder, tower and cable are crucial and are decided based on the strength and stability criteria. Reference [11,12] carried out the optimization of cable stayed 
bridges for cross sectional area of members. The entropy based optimization approach adopted by them will pose limitation in considering many design variables simultaneously. In the present paper all the possible design parameters which affect the optimum cost of bridge, significantly, are considered as design variables and all types of constraints, strength, stability and serviceability are incorporated in the optimization routine.

\subsection{Analysis}

Stiffness method is used for analysis of radiating type of cable stayed bridge using MATLAB. It is assumed that the girder is passing between tower legs and supported on rollers. The cables are fixed to the tower top. Side span is resting on hinge support. For the modeling purposes the cables are considered as no-tension truss elements, girder and tower as beam element. At each node of the beam element three degree of freedom, horizontal, vertical and rotation are considered. For cables only, two degrees of freedoms are considered. The details of bridge geometry are shown in Figure 1. The input parameters of the bridge model are given in Table 1.

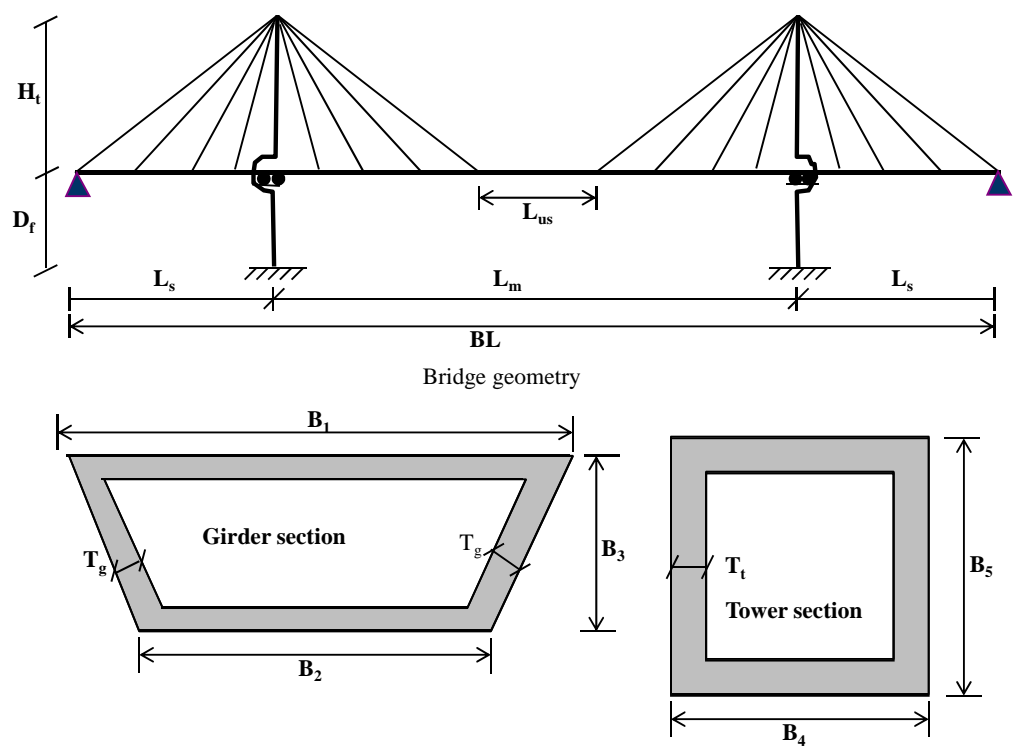

Figure 1. Details of idealized bridge.

Table 1. Input for bridge model.

\begin{tabular}{|c|c|c|c|}
\hline Input for bridge model & Properties & Quantity & Remark \\
\hline Tower & $\mathrm{E}_{\mathrm{t}}$ & $2.1 \mathrm{E}+11 \mathrm{~N} / \mathrm{m}^{2}$ & \\
\hline \multirow[t]{2}{*}{ Girder } & $\mathrm{E}_{\mathrm{g}}$ & $2.1 \mathrm{E}+11 \mathrm{~N} / \mathrm{m}^{2}$ & \\
\hline & $\mathrm{E}_{\mathrm{c}}$ & $1.65 \mathrm{E}+11 \mathrm{~N} / \mathrm{m}^{2}$ & \\
\hline \multicolumn{4}{|l|}{ Cable } \\
\hline & $\mathrm{A}_{\mathrm{c}}$ & 0.01 to $0.10 \mathrm{~m}$ & variable \\
\hline Dead load & $\mathrm{DL}$ & $50 \mathrm{k} \mathrm{N} / \mathrm{m}$ & \\
\hline Live load & LL & $40 \mathrm{k} \mathrm{N} / \mathrm{m}$ & \\
\hline \multicolumn{2}{|c|}{ Ratio of central Unsupported length to main span, $\mathrm{L}_{\mathrm{us}} / \mathrm{L}_{\mathrm{m}}$} & 0.05 to 0.4 & Variable \\
\hline \multicolumn{2}{|c|}{ Ratio of side span to main span, $\mathrm{L}_{\mathrm{s}} / \mathrm{L}_{\mathrm{m}}$} & 0.35 to 0.55 & Variable \\
\hline \multicolumn{2}{|c|}{ Ratio of tower height to main span, $\mathrm{H}_{t} / \mathrm{L}_{\mathrm{m}}$} & 0.2 to 0.4 & Variable \\
\hline \multicolumn{2}{|l|}{ Number of cables } & 8 to 68 & Variable \\
\hline
\end{tabular}




\section{Problem Formulation}

In the present work, the stiffness approach is used to perform nonlinear static analysis of two dimensional cable stayed bridge. Two-dimensional static analysis will be adequate for all practical purposes in optimization of cable stayed bridges. The stiffness method was particularly adopted to handle various types of structural elements such as cables, and beam-column elements and it can be conveniently adopted for computer use. While modeling the connection between girder and tower, the connection node are separately considered and boundary considered are applied independently. In other words, the junction node is not merged. Full geometric nonlinearity, arising from cable sag, beam-column effect and large deformation has been taken in to account while analyzing the structure.

\subsection{Load Cases}

Two main load cases were considered for the final structure, the action of dead load and the action of live load. The action of live load consists of four patterns: over entire deck, over outer spans only, over main span only and over half bridge only. During the optimization the analysis routine analyses the structure for maximum response under any live load pattern at any section. Dead load and live load are accounted for as uniform loads in the stiffening girder as $50 \mathrm{kN} / \mathrm{m}$ and $40 \mathrm{kN} / \mathrm{m}$ respectively. The dead load includes, concrete slab over stiffening girder and the self weight of structural members.

\section{GA Based Formulations}

GA deals with population that is collection of candidate solution. A population is a collection of $\mathrm{N}$ individuals. An important feature of a population, especially in the early generation of its evolution, is its genetic diversity. The too small population size may lead to scarcity of genetic diversity. It may result in a population dominated by almost equal chromosomes and then, after decoding the genes and evaluating the objective function it may converge quickly but may lead to local optimum. At the other extreme, in too large populations, the overabundance of genetic diversity can lead to clustering of individuals around different local optima. But the mating of individuals belonging to different clusters can produce children lacking the good genetic part of either of the parents. In addition, the manipulation of large populations may be excessively expensive in terms of computer time. Thus proper selection of population size is extremely important. Thus over few trials, the population size 60 has been adopted.

The GA based optimization basically depends on three important aspects viz.: 1) coding and decoding of design variables; 2) evaluation of fitness of each solution string; and 3) application of genetic parameters (selection, crossover and mutation) to generate the next generation of solution strings.

\subsection{Design Variables}

The formulation of an optimization problem begins with identifying the underlying design variables. Generally, the parameters such as tower height, unsupported length of main span, side span are expressed as percentage of main span length (Krishna et al., 1985; Hegab, 1988). In the present task the selected design variables are:

- Cable areas $\left(\mathrm{A}_{\mathrm{c}}\right)$,

- Girder depth $\left(\mathrm{B}_{3}\right)$,

- Girder bottom width $\left(\mathrm{B}_{2}\right)$,

- Girder top width $\left(\mathrm{B}_{1}\right)$,

- Girder web thickness $\left(T_{\mathrm{g}}\right)$,

- Tower width $\left(\mathrm{B}_{4}\right)$,

- Tower depth $\left(\mathrm{B}_{5}\right)$,

- Tower web thickness $\left(\mathrm{T}_{t}\right)$,

- Tower height-to-main span ratio $\left(\mathrm{H}_{\mathrm{t}} / \mathrm{L}_{\mathrm{m}}\right)$,

- Side-to-main span ratio $\left(\mathrm{L}_{\mathrm{s}} / \mathrm{L}_{\mathrm{m}}\right)$,

- Central unsupported length-to-main span ratio $\left(\mathrm{L}_{\text {us }} /\right.$ $\mathrm{L}_{\mathrm{m}}$ ),

- Number of cables $\left(\mathrm{N}_{\mathrm{c}}\right)$ and Bridge type (harp or radiating).

\subsection{Coding and Decoding of Variables}

An essential characteristic of genetic algorithm is the coding of variables that describe the problem. The variables in the design space are converted into genetic space by transforming the variables in binary form. The most common coding method is to transform the variables to a binary string of specific length of the chromosome. For a specific problem that depends on more than one variable, a multivariable coding is constructed by simply joining as many single variables coding as the number of variables of the problem. The sequence of variables and the coding for the present problem is illustrated in Figure 2.

\subsection{Objective Function}

In structural design, the dominant objective will be minimizing structural cost. There can be multi objective functions in one problem, but generally it is avoided by choosing the most important objective as the objective func-

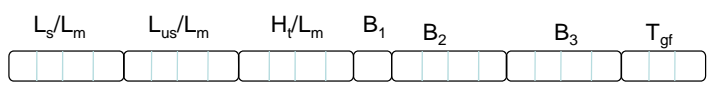

\begin{tabular}{|c|c|c|c|c|c|c|}
\hline $\mathrm{B}_{4}$ & $\mathrm{~B}_{5}$ & $\mathrm{~T}_{\mathrm{tf}}$ & $A_{c 1}$ & $\mathrm{~A}_{\mathrm{c} 2}$ & $A_{c 3}$ & $\mathrm{~A}_{\mathrm{c} 4}$ \\
\hline 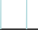 & & & & & & \\
\hline
\end{tabular}

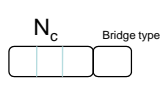

Figure 2. Variable's sequence and coding. 
tion and the other objective functions are included as constraints by restricting their values with in a certain range. The objective function for the present work is expressed in terms of relative cost of bridge material, given by Equation (1). Generally, structural design is required to conform to number of inequality constraints related to stresses, deflection, dimensional relationships, and other codal requirements. These are conveniently handled in genetic algorithms by penalty approach. In this approach a candidate solution is penalized for constraints violation while determining the future use of that solution. The level of penalty depends on the criticality of the role of constraints in objective function. Since design of cable stayed bridge is constrained problem, the objective function should be transformed in to unconstrained problem by introducing an exterior penalty function.

The objective function is expressed in terms of design variables and constraints to be satisfied. Mathematically, for the present problem, for a set of " $x$ " design variables the objective function is expressed in terms of cost of cable, cost of structural steel of tower and girder.

Cost ratio is defined as ratio of cost of cable material per unit volume to the cost of Girder and tower material (steel or concrete) per unit volume. If steel material is used for girder and tower the cost ratio is taken as 2 and if concrete material is used for girder and tower the cost ratio is taken as 10 .

$$
f(x)=\text { Cost ratio } \times \sum_{i=1}^{N_{c}} L_{i} A_{i}+L_{g} A_{g}+2 \times H_{t} A_{t}
$$

where $L_{i}=$ length of $i$ th cable, $A_{i}=$ Area of $i$ th cable; $L_{g}=$ girder length; $A_{g}=$ girder area; $H_{t}=$ tower height; $A_{t}=$ tower area. $N_{c}=$ Number of cables.

The modified objective function with penalty factors is expressed in Equation (2)

$$
\phi(x)=f(x)\left(1+K \sum_{i=1}^{p}\left[\frac{\left|g_{i}\right|}{\left|g_{i}^{a}\right|}-1\right]\right)
$$

If $\left|\frac{g_{i}}{g_{i}^{a}}\right|<1$ the objective function will not be penalized, i.e., $\left|\frac{g_{i}}{g_{i}^{a}}\right|-1=0$.

where $K$ is penalty parameter, $g_{i}^{a}$ is allowable value of constraint $g_{i}, p$ is number of constraints. The penalty parameter is obtained by trial. When the fitness is to be maximized the modified objective function reach to a minimum value.

\subsection{Constraints}

The constraints represent some functional relationships among the design variables and other design parameters satisfying certain physical phenomenon and certain resource limitations. Some of these considerations require that the design remain in static or dynamic equilibrium. All practical types of constraints, related to stress, stability and strength are incorporated in the present work. The constraints have been expressed in normalized form in Equation (3)

$$
\text { constraint violation }_{i}=\frac{\sigma_{i}}{\sigma_{i}^{a}}-1 ;
$$

\subsection{Fitness Evaluation}

The evaluation of the fitness is problem dependent as well. For every individual in the population, a level of fitness must be assigned to it. The fitness of an individual is an indicator of how well an individual is suited to its current environment. Fitness is established by means of a function. Developing this function can be very simple or may be very complex involving a simulation.

The population size is generally selected as approximately equal to chromosome length. As already discussed, the binary coding is more general form of coding in GA and it is easy to implement. In order to retain some number of best individuals at each generation the elitist selection is chosen in GA operator. To reduce positional bias and end-point effect two-point crossover has been chosen and to achieve quick convergence, with few trails the mutation rate was selected. In the optimization of cable stayed bridge the GA parameters considered are listed in Table 2. The process of optimization for the design of cable stayed bridge is illustrated with the help of flowchart given in Figure 3.

\subsection{Pseudo Code for GA Implementation}

$\%$ declare size of population and variables nov $=$ number of variables sop $=$ size of population nob[1: nov]= number of bits for each variable

Step 1: Generate Initial Population for $i=1$ : sop

Table 2. GA input parameters.

\begin{tabular}{cccccc}
\hline Parameter & Coding & Selection & Crossover & Mutation & Population size \\
\hline Method & binary & Elite-count & 2-point; 0.7\% & 0.001 & 60 \\
\hline
\end{tabular}




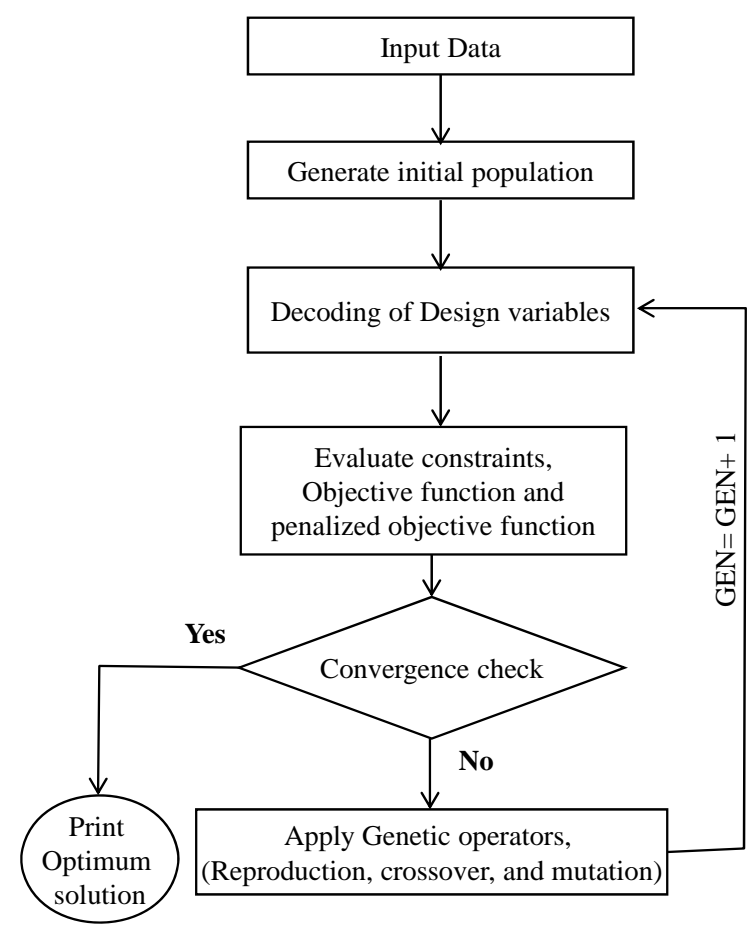

Figure 3. Flow chart for GA optimization.

for $r=1$ : sum(nob) $\operatorname{binpop}(i, r)=$ generate random

number in binary form;

end

end

while (current generation $<=$ maximum generation) $\%$ For each generation do following

\{

Step 2: Binary assignment of variables in chromosomes

Step 3: Fitness Calculations For each chromosome average fitness;

Get structural responses

Compare with permissible values

Penalize the constraint for violation

Modified objective $=$ objective with penalty

Find fitness using modified objective function

Fitness factor $=$ fitness of each chromosome/

Step 4: find index for fittest chromosome

Step 5: Applying Genetic Operators

Elite-count Selection

2 point Crossover

Mutation with appropriate rate

Termination criteria

\section{Parametric Study}

In order to validate the optimization studies parametric studies are carried out. The various parameters such as effect of bridge material, site restriction on tower height, side span, cable layout, effect of cable grouping, geometrical nonlinearity and extra-dosed bridges on optimum relative cost has been studied.

\subsection{Effect of Penalty Parameter on Convergence}

Penalty parameter (K) in Equation (3) is the important parameter which imposes the penalty on objective function based on the constraint violation. In the present problem the penalty parameter is varied from 1 to 9 and the optimization process is carried out. It was observed that higher the penalty parameter longer time taken for convergence as shown in Figure 4. For the present problem by keeping the maximum generations fixed, for higher penalty factor the objective function is more. Depending upon the sensitivity of constraint the constraint violation is penalized. Unnecessarily increasing the penalty constant will take solution far away from boundary leading to late convergence. Thus the $K=1$ is appropriate for the present problem.

\subsection{Effect of Bridge Material on Optimum Relative Cost}

The material considered for the present study of cable stayed bridge, are as follows:

1) Tower and deck/girder as concrete and cable high tensile steel;

2) Tower and deck/girder as steel and cables as high tensile steel.

For the calculation of cost, the cost ratio of cable steel to structural steel is taken as 2. While studying the concrete bridge the cost ratio of cable to concrete is taken as 6,8 and 10. The optimum relative cost for both cases is

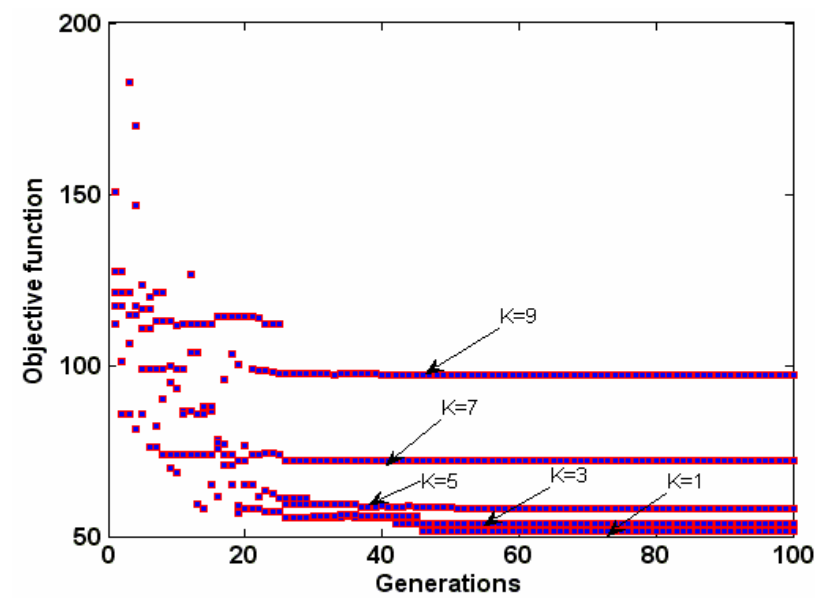

Figure 4. Effect of penalty parameters on objective function. 
compared in Figure 5. It is observed that for $500 \mathrm{~m}$ bridge even with cost ratio of 10 the reduction in steel cost is $45 \%$. It indicates that for long span bridges it is advisable to use steel than concrete.

\subsection{Effect of Geometric Nonlinearity on Relative Bridge Cost}

The results of design optimization using linear and nonlinear analysis are shown in Figure 6. In this figure, the optimum relative cost of four bridges with bridge lengths of $60 \mathrm{~m}$ to $500 \mathrm{~m}$ are presented using both linear (firstorder) and nonlinear (second-order) analysis results. It can be seen that there is an increase in optimum cost if nonlinear analysis results are used for bridge lengths above $250 \mathrm{~m}$. This increase is proportionate to the bridge length. For the bridge length of $150 \mathrm{~m}$, there is an increase of $13 \%$ in the optimum cost due to consideration of nonlinear effects. For higher bridge lengths, the increase can be much more.

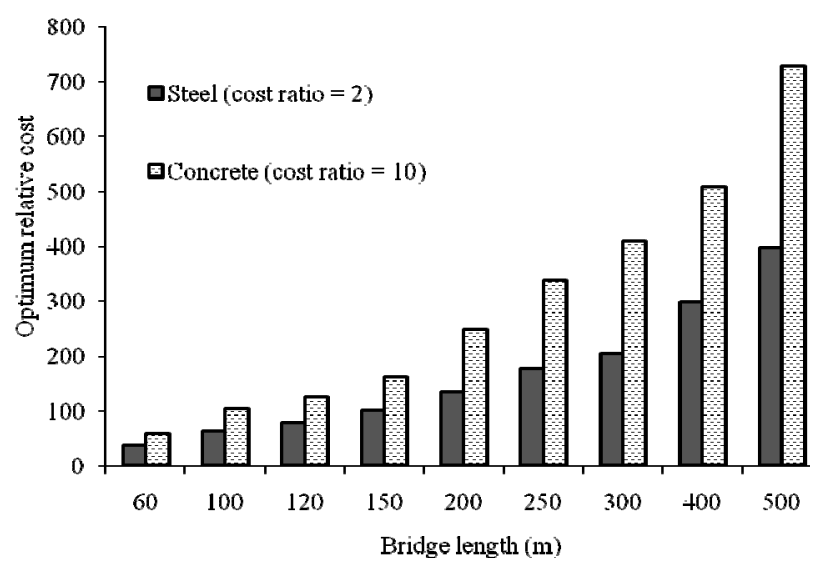

Figure 5. Effect of bridge material.

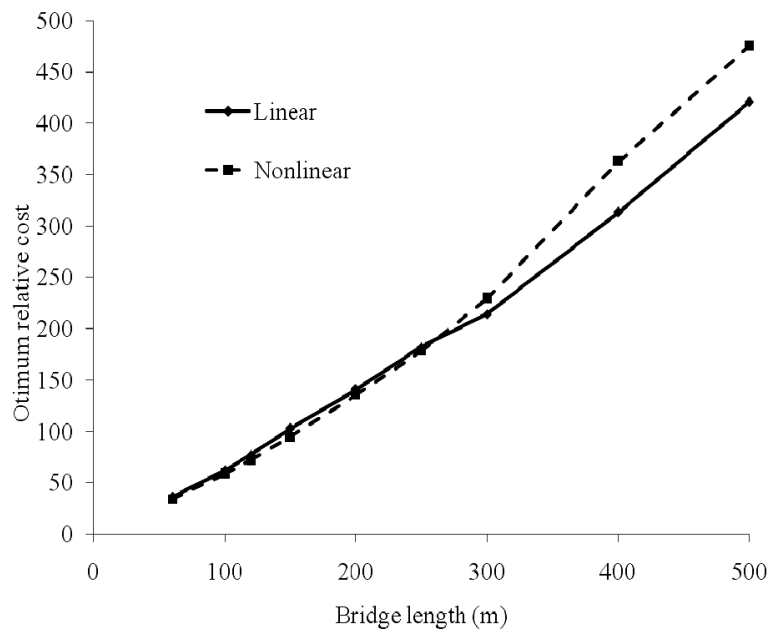

Figure 6. Effect of geometrical nonlinearity on optimum relative cost.

\subsection{Effect of Grouping of Cables}

GA-based design optimization on two types of bridges: 1) bridge with the same cross-section for all the cables; 2) bridge with four different cross-sections for cables in four zones. The effect on optimum relative cost of cable material has been studied. It is observed from the Figure 7 that from $120 \mathrm{~m}$ bridge length the grouping of cable will reduce the optimum cost by $5 \%$. Instead of adopting the same area for all the cables, it is advantageous to give larger areas to outer most cables with respect to pylon and lesser areas to interior cables. For this purpose, the cables in the bridge are divided into four zones. It is observed that reduction in the cost is directly affected by the reduction in the cable volume.

\subsection{Effect of Practical Site Constraints: Tower Height}

Many a times the optimum ratio for tower height-to-main span ratio may have to be altered based on site conditions. In such situation, for given tower height-to-main span ratio the optimization is carried out to get the optimum cost. In the present work the practical tower height-tomain span ratios $0.1,0.2,0.3$, and 0.4 are considered. For all these ratios the optimization study has been conducted. It is observed from Figure 8 that as bridge length is increasing the optimum tower height-to-main span ratio has shifted from 0.2 to 0.4 .

\subsection{Effect of Optimum Side-to-Main Span Ratio on Relative Cost}

In some situations the designer is restricted to use particular side-to-main span ratio based on site conditions. For that purpose this study is conducted to facilitate the designer to get optimum cost for the restricted side-tomain span ratio. The ratios studied here are $0.2,0.35,0.4$, $0.45,0.5,0.55$, and 0.75 . The relative optimum cost for each bridge length has been studied. It has been observed

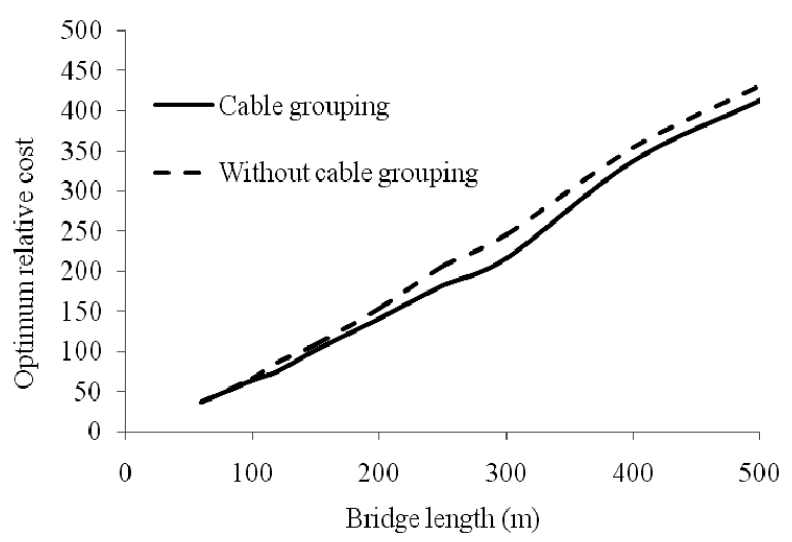

Figure 7. Effect of grouping of cables on optimum relative cost. 


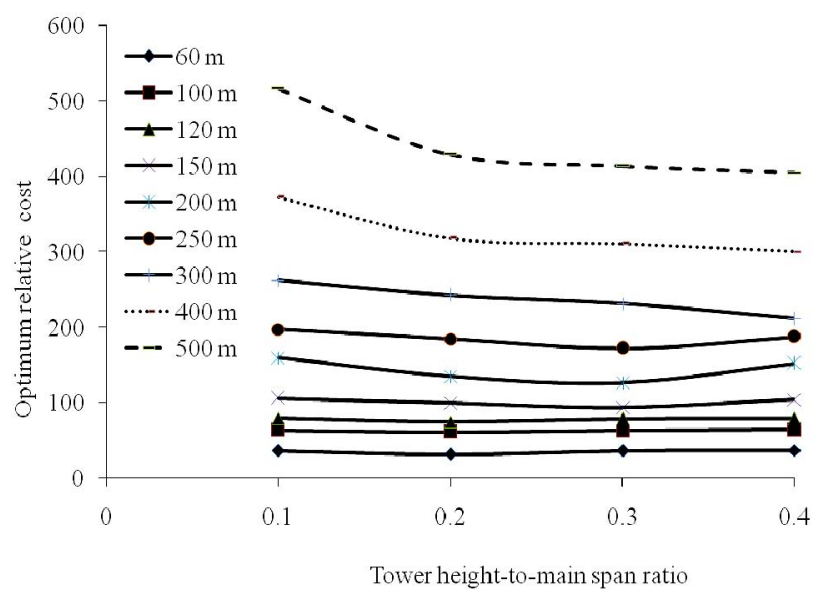

Figure 8. Effect of tower height restriction on relative optimum cost.

from Figure 9 that as bridge length increases the optimum side-to-main span ratio decreases from 0.55 to 0.35 . This study reveals the fact that although the practical range of side-to-main span ratio is 0.35 to 0.55 the exact ratio for particular bridge length can thus be obtained.

\subsection{Effect of Practical Site Constraints: Cable Lay Out}

Two types of cable layout are considered for the present studies, one with radiating type and second with harp type. Although it is a design variable, still for the purpose detailed understanding the effect of cable layout this study has been carried out. The optimum design results are compared for two types of cable layout by restricting the design variable to particular cable layout. The relative optimum cost is plotted with respect to various bridge lengths in Figure 10. Keeping all parameters same, only relative optimum cost variation is compared. It is observed that for up to $300 \mathrm{~m}$ bridge length the optimum cost has no difference. Above $300 \mathrm{~m}$ bridge lengths the radiating type of bridge cost around $5 \%$ to $12 \%$ less. Hence the radial type is recommended from economy point of view when the static case is considered.

\subsection{Effect of Extra-Dosed Bridge}

The extra-dosed bridges are designed for lesser tower heights. For this study the tower height-to-main span ration has been restricted to 0.05 to 0.2 . The study revealed that the extra-dosed bridge found to be $3 \%$ economical up to $250 \mathrm{~m}$ bridge length (Figure 11). But beyond the bridge length of $300 \mathrm{~m}$ the extra-dosed bridges are costlier around $12 \%$ as compared to ordinary cable stayed bridges.

\section{Summary and Conclusions}

GA is robust tool for optimization. In the present work stiffness based analysis approach is used for cable stayed bridge. Considering all the practical constraints and most crucial design variables the optimum design studies are

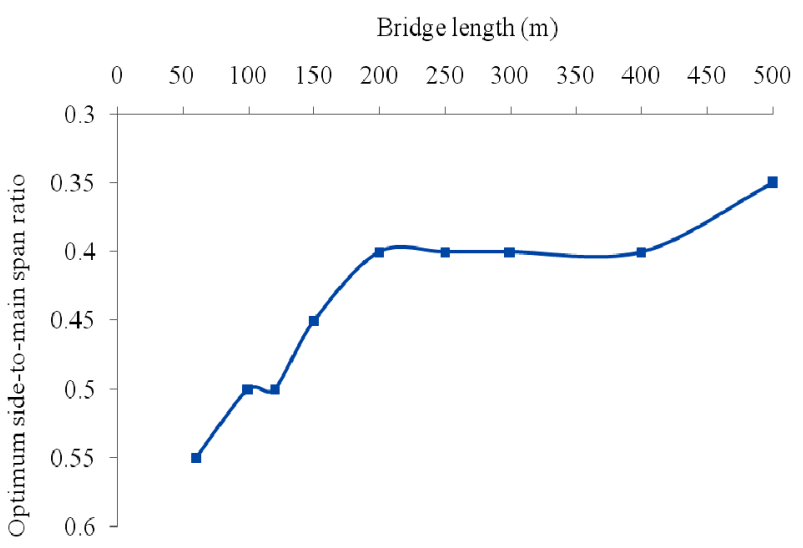

Figure 9. Optimum side-to-main span ratio.

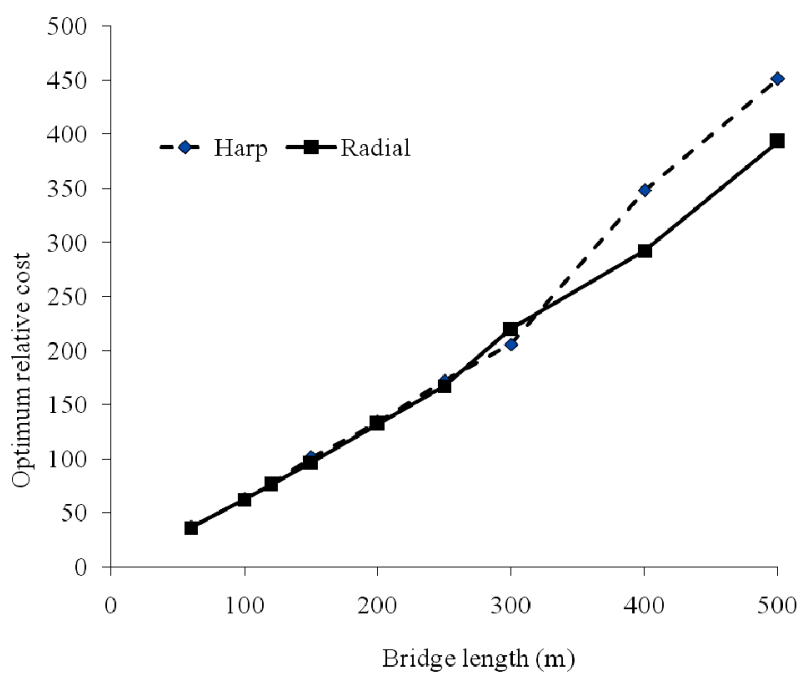

Figure 10. Effect of cable layout on optimum relative cost.

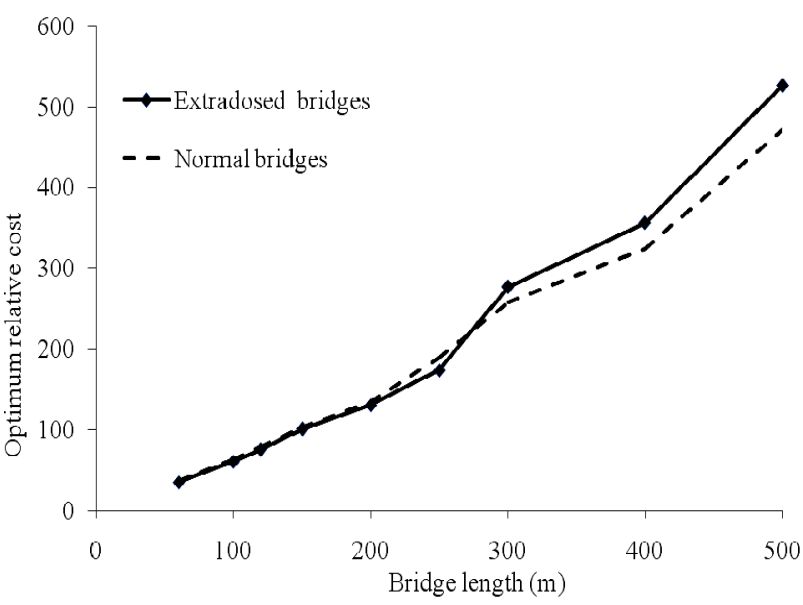

Figure 11. Effect of extradosed bridges on optimum cost. 
carried out using genetic algorithms. The following conclusions are drawn from the present work:

- GA can handle more number of variables easily. The developed GA program is more general to accommodate discrete and continuous variables

- Effect of bridge material study reveals that for $60 \mathrm{~m}$ bridge length decrease in relative cost for steel bridge is around 25\%. As bridge length increases from $60 \mathrm{~m}$ to $500 \mathrm{~m}$ there is increase in the reduction in steel bridge cost up to $45 \%$ as compared to concrete bridge cost.

- Due to inclusion of cable grouping concept in the current optimization approach, reduction in the relative cost is observed. As bridge length increases from $60 \mathrm{~m}$ to $500 \mathrm{~m}$ the reduction in relative optimum cost varies between $5 \%$ to $13 \%$. It is expected more when the bridge length increases beyond $500 \mathrm{~m}$ and in situations where cable numbers are more.

- By incorporating the geometric nonlinearity in the analysis of cable stayed bridge in optimization approach up to $200 \mathrm{~m}$ bridge length there is hardly any difference in optimum relative cost. An increase in optimum relative cost was observed for bridge length ranging from $250 \mathrm{~m}$ to $500 \mathrm{~m}$ up to $13 \%$.

- It is observed, by restricting the tower height, that the optimum tower height-to-main span ratio is shifted from 0.2 to 0.4 as bridge length increased from $60 \mathrm{~m}$ to $500 \mathrm{~m}$.

- The effect of optimum side-to-main span ratio on optimum relative cost study revealed that the optimum side-to-main span ratio is changing from 0.55 to 0.35 as bridge length increases from $60 \mathrm{~m}$ to $500 \mathrm{~m}$. The side-to-main span ratio is shifted towards 0.35 following s-curve pattern.

- When the cable layout is restricted to radial type only, up to $300 \mathrm{~m}$ bridge length the difference in optimum relative cost is negligible. Beyond $300 \mathrm{~m}$ length, it has been observed that radial-type cable layout can result in reduction of the optimum cost by $5 \%-12 \%$ from the bridge with harp type cable layout.

The data base prepared for various practical bridge lengths will be beneficial for designers to estimate the cost of cable stayed bridges.

\section{REFERENCES}

[1] M. S.Troitsky, "Cable-Stayed Bridges: Theory and Design,” Crosby Lockwood Staples, London, 1972.

[2] M. Y. H. Bangash, "Prototype Bridge Structures: Analysis and Design,” Thomas Telford Publisher, London, 1999.

[3] W. Podolny and J. B. Scalzi, "Construction and Design of Cable Stayed Bridges,” John Wiley and Sons, New York, 1986.

[4] P. Krishna, A. S. Arya and T. P. Agrawal, "Effect of Cable Stiffness on Cable-Stayed Bridges,” Journal of Structural Engineering, Vol. 111, No. 9, 1985, pp. 2008-2020.

[5] H. I. A. Hegab, "Parametric Investigation of Cable Stayed Bridges,” Journal of Structural Engineering, Vol. 114, No. 8, 1988, pp. 1917-1928. doi:10.1061/(ASCE)0733-9445(1988)114:8(1917)

[6] D. Shi and Y. M. Xu, "Optimum Design of Cable Stayed Bridges with Multi Variables. Computing in Civil and Building Engineering,” Pahi \& Werner Edition, Rotterdam, 1995.

[7] P. K. Singh and P. K. Mallick, "Optimum Cost Solution for Cable-Stayed bridges,” Journal of the Indian National Group of the International Association for Bridge and Structural Engineering, Vol. 32, No. 1, 2002, pp. 51-72.

[8] C. S. Krishnamoorthy, P. P. Venkatesh and R. Sudarshan, "Object-Oriented Framework for Genetic Algorithms with Application to Space Truss Optimization,” Journal of Soft Computing in Civil Engineering, Vol. 16, No. 1, 2002, pp. 66-75. doi:10.1061/(ASCE)0887-3801(2002)16:1(66)

[9] A. Upadhyay and V. Kalyanaraman, "Optimum Design of Fibre Composite Stiffened Panels Using Genetic Algorithms," Engineering Optimization, Vol. 33, 2000, pp. 201-220.

[10] V. Srinivas and K. Ramanjaneyulu, “An Integrated Approach for Optimum Design of Bridge Decks Using Genetic Algorithms and Artificial Neural Networks," Advances in Engineering Software, Vol. 38, No. 7, 2007, pp. 475-487. doi:10.1016/j.advengsoft.2006.09.016

[11] L. M. C. Simoes and J. H. O. Negrao, "Sizing and Geometry Optimization of Cable-Stayed Bridges,” Computers and Structures, Vol. 52, No. 2, 1994, pp. 309-321. doi:10.1016/0045-7949(94)90283-6

[12] J. H. O. Negrao and L. M. C. Simoes, "Optimization of Cable Stayed Bridges with Three Dimensional Modeling," Computers and Structures, Vol. 64, No. 1-4, 1997, pp. 741-758. doi:10.1016/S0045-7949(96)00166-6 